\title{
Complete Resolution of Type 1 Refractory Celiac Disease after Combined Treatment with Budesonide and Azathioprine: A Case Report and Literature Review
}

\author{
Juan Sebastian Lasa* \\ Gastroenterology Section, Internal Medicine Department, Centro de Educación Médica e Investigación Clínica (CEMIC), \\ Buenos Aires, Argentina \\ *Corresponding author: drjuanslasa@gmail.com
}

Received Jnauary 01, 2015; Revised January 07, 2015; Accepted January 11, 2015

\begin{abstract}
Refractory Celiac Disease is a rare condition associated with a substancial mortality rate. Both treatment and follow-up are still matter of debate. The case of a 54 year-old man with refractory celiac disease is presented who required treatment with both budesonide and azathioprine. A concise review of the clinical Management of Refractory Celiac Disease is then performed.
\end{abstract}

Keywords: celiac disease, diet, gluten free, lymphoma

Cite This Article: Juan Sebastian Lasa, "Complete Resolution of Type 1 Refractory Celiac Disease after Combined Treatment with Budesonide and Azathioprine: A Case Report and Literature Review." International Journal of Celiac Disease, vol. 3, no. 1 (2015): 40-43. doi: 10.12691/ijcd-3-1-3.

\section{Introduction}

Refractory celiac disease (RCD) is a rare condition that is associated with both high complication and mortality rates. Immunosupressants have been proposed as a therapeutic option; however, evidence is scarce and treatment as well as follow up of this condition is still a matter of debate. A case of a celiac disease (CD) patient that developed a type-1 RCD that was treated with combination therapy with budesonide and azathioprine is presented.
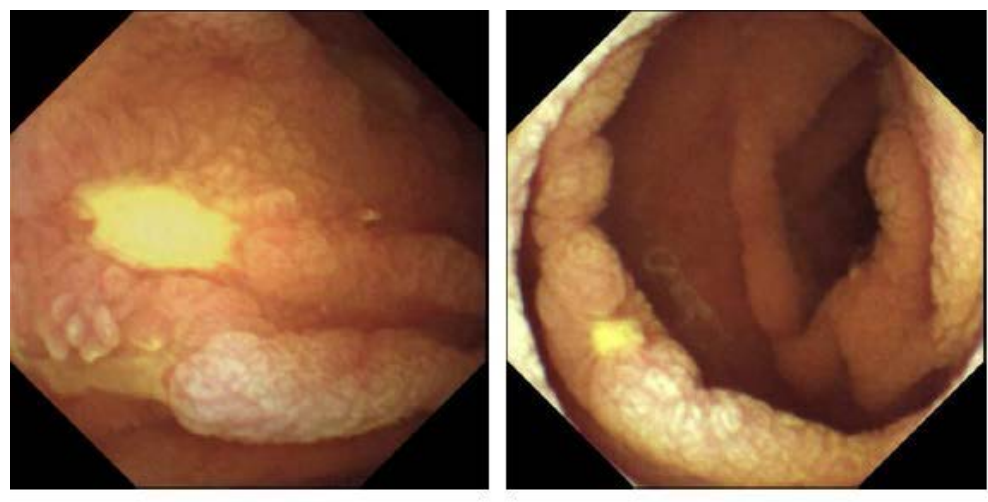

$01: 47: 15$

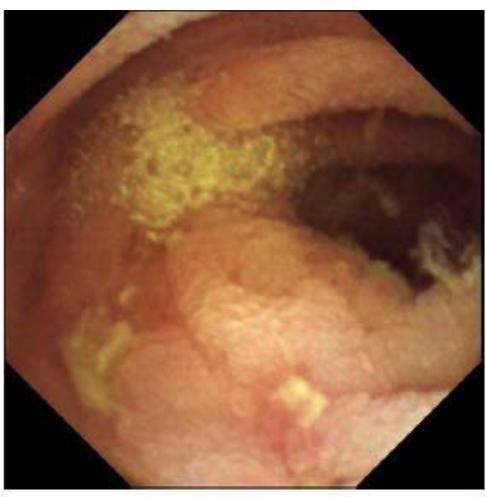

$01: 57: 08$

Figure 1. Capsule endoscopy showing ulcerative jejunitis (Mirocam)

\section{Case Report}

A 54 year-old man was admitted to our institution due to severe diarrhea and hypokalemia that started two weeks before admission. He was diagnosed of CD two years ago: he presented positive IgA anti-transglutaminase (tTG) antibodies (252 U/ml) on diagnosis as well as total villous atrophy (Marsh IIIC) on duodenal biopsies. On admission, the patient was pale, with a marked abdominal distention and peripheral oedema. Laboratory results revealed microcytic anemia $(\mathrm{Hb}=9.5 \mathrm{gr} / \mathrm{dl} ; \mathrm{MCV}=75), \mathrm{K}+=2.7$ $\mathrm{mEq} / \mathrm{l}$, hypoalbuminemia (2.8 gr/l). Anti-tTG as well as anti-endomysium and anti-gliadin antibodies were negative; HIV serology was negative and IgG levels were slightly increased. Nutritional assessment confirmed strict adherence to gluten-free diet (GFD). Upper endoscopy showed typical villous atrophy endoscopic findings and colonoscopy showed no relevant findings. Duodenal biopsies showed severe villous atrophy with increased 
number of intraepithelial lymphocytes (IELs= >30/HPF) and ruled out findings compatible with Whipple's disease or giardiasis. Colon biopsies excluded microscopic colitis. Stool analysis ruled out the presence of Giardia or other parasites. CT-enteroclysis showed a significant thickening of the jejunal wall; capsule endoscopy was performed (Figure 1) which revealed multiple ulcers throughout the proximal jejunum, compatible with ulcerative jejunitis. PET Scan did not show any abnormal tracer uptake. Single-balloon enteroscopy was undertaken in order to take multiple jejunal biopsies: immunophenotype analysis did not show aberrant IELs: these expressed surface CD3, CD8 and TCR- $ß$ and without TCR rearrangement (Figure 2). A diagnosis of type-1 refractory celiac disease (RCD) was done.

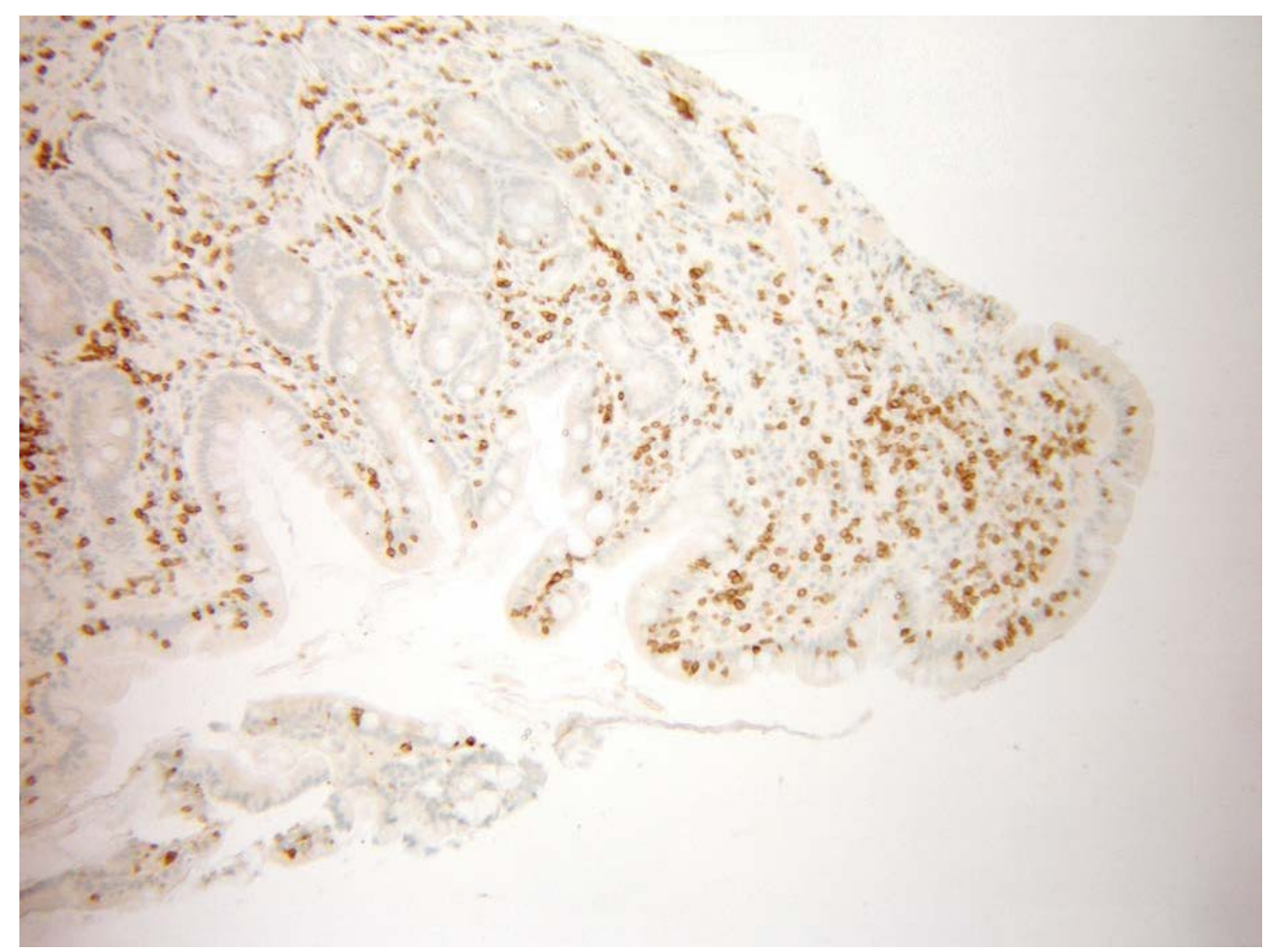

Figure 2. Jejunal biopsy with immunohistochemical analysis

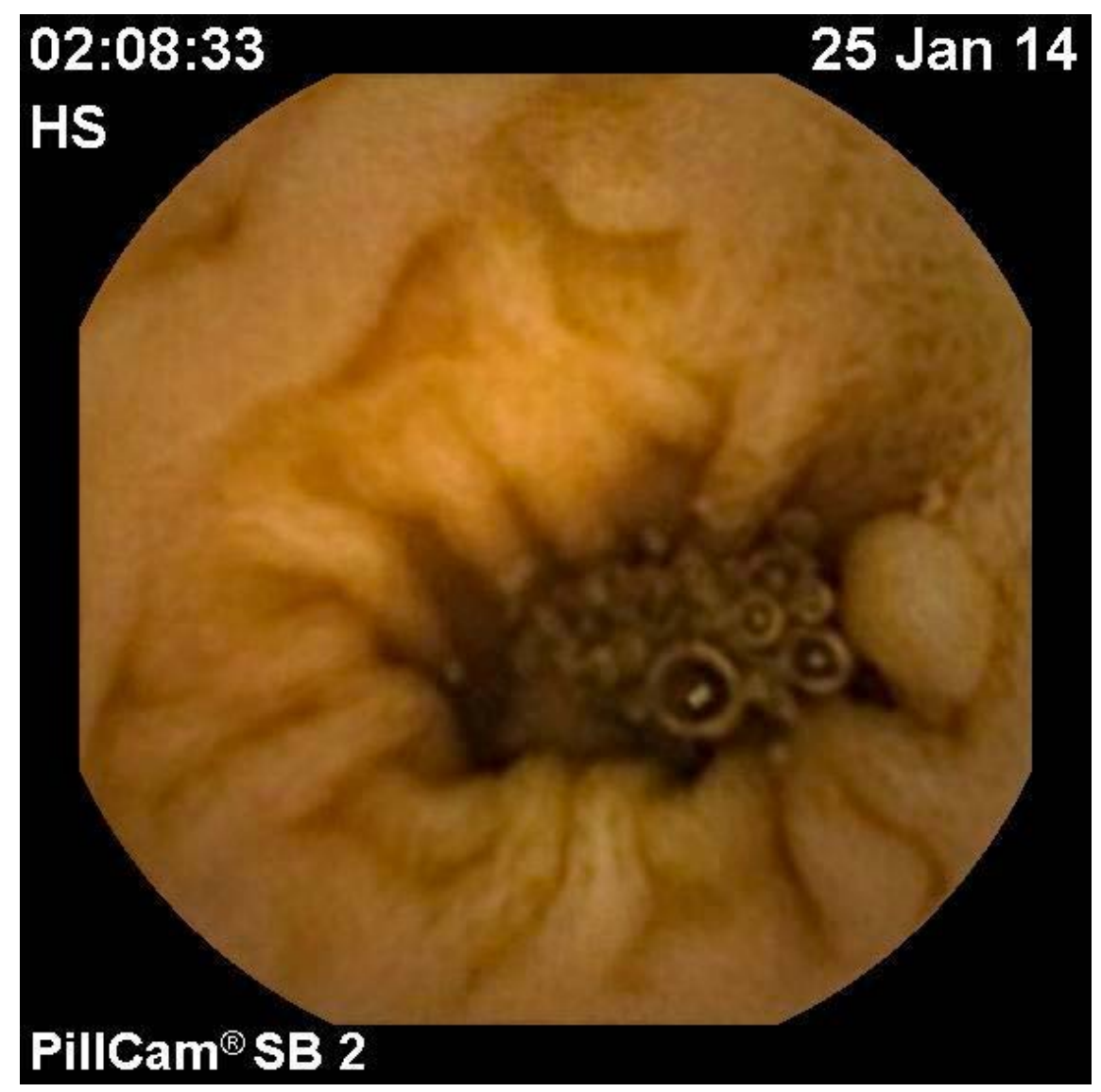

Figure 3. Second capsule endoscopy performed after treatment 
Treatment with $9 \mathrm{mg}$ of budesonide was initiated. After clinical improvement, the patient was discharged. After two months of treatment, the patient did not experienced complete resolution of his symptoms. Azathioprine was then added at a $2 \mathrm{mg} / \mathrm{kg}$ dose. Budesonide dose was slowly tapered. After six months of combined treatment, a complete resolution of symptoms was achieved; the patient continued on azathioprine treatment. After twelve months, CT-enteroclysis was normal and a capsule endoscopy was repeated, which showed a complete endoscopic resolution of jejunal ulcers (Figure 3). Repeat endoscopy showed a significant histological improvement. Azathioprine treatment was discontinued.

\section{Discussion}

CD is a chronic inflammatory disorder that affects the small intestine in genetically susceptible individuals [1]. It is caused by the ingestion of gluten present in cereals such as wheat, barley and rye, and improvement is usually observed after initiation of a strict GFD [2]. Nonresponsive $\mathrm{CD}$ is defined as the lack of clinical and/or histological improvement after 6-12 months of GFD; in many cases, inadvertent exposure to gluten may be the cause [3], but in a small percentage of cases, malabsortive symptoms may be due to persistent villous atrophy and severe inflammation despite strict adherence to GFD: this is known as RCD [4].

RCD is typically divided into two subgroups: types 1 (RCD 1) and 2 (RCD 2). The distinction of these categories is based on the detection of abnormal intraepithelial lymphocyte phenotype (which is the hallmark of RCD 2): this is determined by the presence of aberrant lymphocytes using CD3/CD8 immunochemistry and T-cell receptor (TCR) clonal rearrangement (by means of polymerase chain reaction or flow cytometry). The characterization of aberrant T-cells seems to have a prognostic impact, since it is a strong predictor of enteropathy-associated T-cell lymphoma (EATL) [5]. Thus, RCD 2 carries a poorer progonosis, with an elevated short-term mortality [6]. The prognosis of RCD 1 is much better as compared to RCD 2 but the rates of complications and mortality appear to be much higher than those observed in non-complicated CD [7]. Ulcerative jejunitis is an endoscopic feature that can be present in both RCD 1 and RCD 2; although the evidence is scarce, its presence should prompt the exclusion of EATL; also, prognosis seems to be worse in RCD 1 with ulcerative jejunitis than those without this finding [8].

There is a tendency towards treating RCD 2 as a neoplastic condition; as a consequence, treatment with chemotherapic agents, such as cladribine $[9,10]$ or even autologous hematopoietic stem cell transplantation [11] have been used as therapeutic alternatives. Immunosuppressive agents seem to be more eficacious in RCD 1 patients.

Since RCD is an uncommon condition with a poor prognosis, there are very few studies assessing the efficacy of potential treatments. In addition, methodological quality of published studies is far from ideal, due to logical difficulties in recruiting patients and ethical aspects. Typically, prednisone (0.5-1 mg/kg/day) or budesonide (9mg/day) have been used as initial treatment options $[12,13]$. Budesonide seems to be a more attractive alternative, since it shows a better safety profile when compared to prednisone, due to its extensive first-pass metabolism. However, the main concern with these options is the development of steroid-dependency, specially in patients without a rapid response [14].

Azathioprine constitutes a valid therapeutic option in this clinical scenario. Mauriño et al [15] showed in a small open-label trial a good response to the addition of azathioprine in those RCD subjects that had started treatment with prednisone. Moreover, Goerres et al [16] demonstrated that the combination therapy with azathioprine plus corticosteroids constitutes a valid therapeutic option for RCD 1 (80\% experienced clinical improvement) with unsatisfactory results in those patientds with RCD 2.

There is no evidence on the long-term efficacy of treatment in patients with RCD. The optimal treatment and the adequate follow-up is still a matter of debate. Although effective, azathioprine should be used cautiously because of potentially serious side effects [17]. Among these, the risk of lymphoma development raises particular concern, as observed in published studies of thiopurines use in other conditions, such as inflammatory bowel disease [18]. Since RCD can have a high risk of EATL development, chronic exposure to azathioprine could be a potential risk factor for lymphomagenesis in this population. This is the reason why, after witnessing a clinical and endoscopic resolution and significant histological improvement, we decided to discontinue azathioprine.

Follow-up should be strict and thorough: apart from repeated intestinal biopsies, a complete evaluation of the small intestine seems to be relevant. For this matter, Capsule Endoscopy offers an useful and non-invasive tool for this purpose. CT-enterography may be another option; in this case, we found a good correlation between tomographic and capsule endoscopic findings before and after treatment.

\section{Conclusions}

This case report describes a patient with a diagnosis of RCD 1 that was successfully treated with a combined treatment of budesonide and azathioprine after an initial treatment of budesonide. It was also documented the value of capsule endoscopy and CT-enterography as follow-up tools in this kind of patients.

\section{References}

[1] Di Sabatino A, Corazza GR. Coeliac disease. Lancet 2009; 373: 11480-93.

[2] Murray JA, Watson T, Clearman B, Mitros F. Effect of a glutenfree dieron gastrointestinal symptoms in celiac disease. Am J Clin Nutr 2004; 79: 669-73.

[3] Daum S, Cellier C, Mulder CJ. Refractory coeliac disease. Best Pract Res Clin Gastroenterol 2005; 19: 413-24.

[4] Rubio-Tapia A, Murray JA. Classification and Management of refractory celiac disease. Gut 2010; 59:547-57.

[5] Al-Toma A, Verbeek WH, Hadithi M, von Blomberg BM, Mulder CJ. Survival in refractory coeliac disease and enteropathyassociated T-cell lymphoma: retrospective evaluation of singlecentre experience. Gut 2007; 56: 1373-8.

[6] Malamut G, Afchain P, Verkarre V, Lecomte T, Amiot A, Damotte D, Bouhnik Y, Colombel JF, Delchier JC, Allez M, Cosnes J, Lavergne-Slove A, Meresse B, Trinquart L, MacIntyre E, Radford-Weiss I, Hermine O, Brousse N, Cerf-Bensussan N, Cellier C. Presentation and long-term follow up of refractory 
celiac disease: comparison of type I with type II. Gastroenterology 2009; 136: 81-90.

[7] Al-Toma A, Verbeek WH, Mulder CJ. Update on the Management of refractory coeliac disease. J Gastrointestin Liver Dis 2007; 16: 57-63.

[8] Ashton-Key M, Diss T, Pan L, Du MQ, Isaacson PG. Molecular analysis of T-cell clonality in ulcerative jejunitis and enteropathyassociated T-cell lymphoma. Am J Pathol 1997; 151: 493-98.

[9] Al-Toma A, Goerres MS, Meijer JW, von Blomberg BM, Wahab PJ, Kerckhaert JA, Mulder CJ. Cladribine therapy in refractory celiac disease with aberrant T cells. Clin Gastroenterol Hepatol. 2006; 4: 1322-7.

[10] Tack GJ, Verbeek WH, Al-Toma A, Kuik DJ, Schreurs MW, Visser O, Mulder CJ. Evaluation of cladribine treatment in refractory celiac disease type II. World J Gastroenterol 2011; 17: 506-513.

[11] Al-Toma A, Visser OJ, van Roessel HM, von Blomberg BM, Verbeek WH, Scholten PE, Ossenkoppele GJ, Huijgens PC, Mulder CJ. Autologous hematopoietic stem cell transplantation in refractory celiac disease with aberrant T cells. Blood 2007; 109: 2243-49.

[12] Daum S, Ipczynski R, Heine B, Schulzke JD, Zeitz M, Ullrich R. Therapy with budesonide in patients with refractory sprue Digestion. 2006; 73: 60-8.
[13] Brar P, Lee S, Lewis S, Egbuna I, Bhagat G, Green PH. Budesonide in the treatment of refractory celiac disease. Am J Gastroenterol. 2007; 102: 2265-9.

[14] Rubio-Tapia A, Kelly DG, Lahr BD, Dogan A, Wu TT, Murray JA. Clinical staging and survival in refractory celiac disease: a single center experience. Gastroenterology. 2009; 136:99-107.

[15] Mauriño E, Niveloni S, Cherñavsky A, Pedreira S, Mazure R, Vazquez H, Reyes H, Fiorini A, Smecuol E, Cabanne A, Capucchio M, Kogan Z, Bai JC. Azathioprine in refractory sprue: results from a prospective, open-label study. Am J Gastroenterol 2002 Oct; 97(10): 2595-60.

[16] Goerres MS, Meijer JW, Wahab PJ, Kerckhaert JA, Groenen PJ, Van Krieken JH, Mulder CJ. Azathioprine and prednisone combination therapy in refractory coeliac disease. Aliment Pharmacol Ther. 2003; 18: 487-94.

[17] Connell WR, Kamm MA, Dickson M, Balkwill AM, Ritchie JK, Lennard-Jones JE. Long-term neoplasia risk after azathioprine treatment in inflammatory bowel disease. Lancet. 1994; 343: 1249-52.

[18] Herrinton LJ, Liu L, Weng X, Lewis JD, Hutfless S, Allison JE. Role of thiopurine and anti-TNF therapy in lymphoma in inflammatory bowel disease. Am J Gastroenterol. 2011 Dec; 106(12): 2146-53. 